\title{
Two Labelings Techniques for Corona Graph $\mathrm{C}_{\mathrm{n}}{ }^{{ } \mathrm{K}_{1}}$
}

\author{
Veena Shinde-Deore. \\ Head, Department of Mathematics \\ \& Statistics, \\ Bhavan's H.S. College, Mumbai. \\ Research Scholar, JJT University.
}

\author{
Manisha M.Acharya, PhD. \\ Associate Professor and Head, \\ Department of Mathematics, \\ Maharshi Dayanand College, Parel, Mumbai. \\ Research Guide ,JJT University.
}

\begin{abstract}
Labeling of graphs is an assignment of integers to the vertices or edges or both using some conditions. There are various labelings techniques such as feliticious labeling, graceful labelings, harmonious labeling, magic labeling etc. applied to certain classes of graphs. H-cordiality is proved for wheels, generalized Peterson graph, triangular graph and special ladder. In this paper, $\mathrm{H}$-cordial labeling and prime labelings of the corona graph $\mathrm{C}_{\mathrm{n}} * \mathrm{~K}_{1}$ for $\mathrm{n} \geq 3$ is obtained.
\end{abstract}

\section{Keywords:}

Graph labeling, integers, feliticious labeling, graceful labelings, harmonious labeling, magic labeling, H-cordial labeling, prime labelings, corona graph.

\section{INTRODUCTION}

In a graph $\mathrm{G}$, an assignment of integers to the vertices or edges or both using certain conditions is called labeling of graph [1]. Most of the terminologies and notations are taken from Harary [6].Some survey of graph labelings is done from Gallian[7].Let $\mathrm{V}(\mathrm{G})$ denote the vertex set and $\mathrm{E}(\mathrm{G})$ denote the set of edges. The graph $G$ is denoted as ordered pair of $V(G)$ and $E(G)$ i.e. $\mathrm{G}=(\mathrm{V}(\mathrm{G}), \mathrm{E}(\mathrm{G}))$. There are many types of labelings techniques. Some of them are feliticious labeling, graceful labelings, harmonic labeling, magic labeling etc. applied to certain classes of graphs.

\section{PRELIMINARIES AND NOTATION}

Here, in this part, the basic definitions are given for development of paper.

Definition 1: A graph $G[6]$ is a pair $(V(G), E(G))$ where $V(G)$ is a nonempty finite set of elements known as vertices and $E(G)$ is family of unordered pairs of elements of $V(G)$ known as edges.
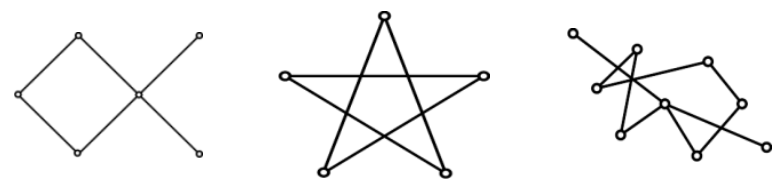

Figure 1:Different graphs.

Definition 2: Labeled graph: When the vertices or lines in a graph are labeled with numbers we call it a 'labeled graph' [6]. Labeling $f$ of the vertices of a graph $G$ is an assignment of distinct natural numbers to vertices of $\mathrm{G}$. The weight induced by $f$ on each edge $e=(u, v)$ of $G$ is the number $|f(u)-f(v)|$.
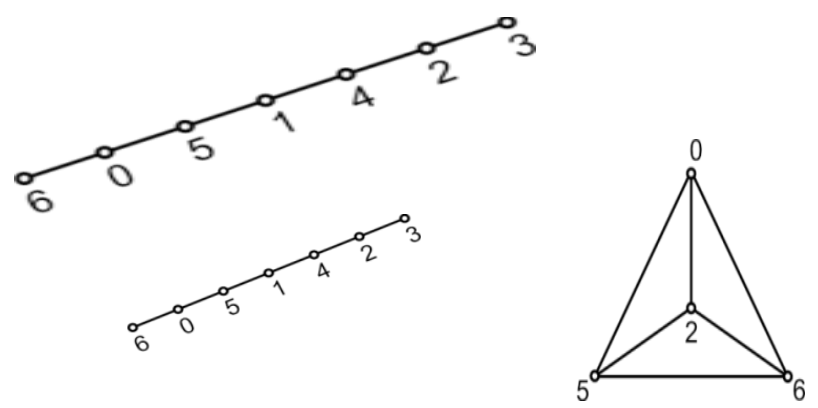

Figure 2:Labeling of graphs.

Definition 3: The corona $\mathbf{G}_{1} * \mathbf{G}_{2}$ [6] of two graphs $\mathrm{G}_{1}$ and $\mathrm{G}_{2}$ is graph $G$ obtained by taking one copy of $G_{1}$ which has $p_{1-}$ vertices and $p_{1}$-copies of $G_{2}$ and then joining $i^{\text {th }}$ vertex of $G_{1}$ to every vertex in the $i^{\text {th }}$ copy of $G_{2}$.

Here we have shown the corona $\mathrm{C}_{3} * \mathrm{~K}_{1}$

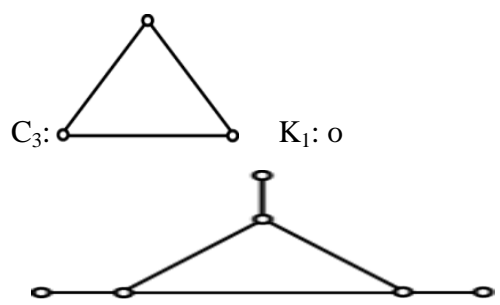

Figure 3: Corona $\mathrm{C}_{3} * \mathrm{~K}_{1}$

Definition 4: Let $\mathrm{G}$ be a graph with q edges.

Let $\mathrm{f}$ be labeling of $\mathrm{G}$ such that the set of labels of vertices is a subset of $\{0,1,2,3, \ldots, q\}$ and the set of the edge labels is from set $\{1,2,3, \ldots \ldots, q\}$ Then the labeling $f$ is said to be graceful[7] and graph $\mathrm{G}$ is called graceful graph.

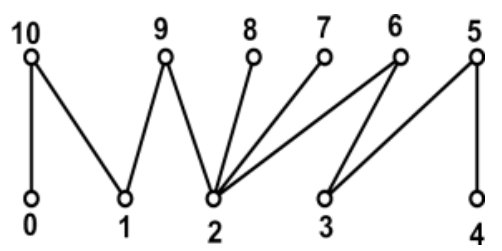

Figure 4: Graceful graphs.

Yilmaz and Cahit(1997) introduced edge cordial labeling[13]

Definition 5: It is possible to label the edges with the numbers from the set $\mathrm{N}=\{+1,-1\}$ in such a way that at each vertex $\mathrm{v}$, the algebraic sum of the labels on the edges incident with $\mathrm{v}$ is either $+\mathrm{k}$ or $-\mathrm{k}$ and the inequalities $\left|\mathrm{v}_{\mathrm{f}}(+\mathrm{k})-\mathrm{v}_{\mathrm{f}}(-\mathrm{k})\right| \leq 1$ and $\mathrm{le}_{\mathrm{f}}(+1)-\mathrm{e}_{\mathrm{f}}(-1) \mid \leq 1$ are also satisfied, where $\mathrm{v}_{\mathrm{f}}(\mathrm{i})$ and $\mathrm{e}_{\mathrm{f}}(\mathrm{j})$ are 
respectively the number of vertices labeled with $i$ and number of edges labeled with $\mathrm{j}$. Such a labeling is called $\mathrm{H}$-cordial labeling. A graph $\mathrm{G}=(\mathrm{V}, \mathrm{E})$ is called $\mathrm{H}$-cordial if it admits an H-cordial labeling $[8,13]$.

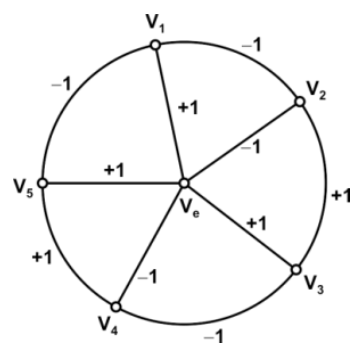

Figure 5: H-cordial graph: wheel $\mathrm{W}_{5}$

\section{Definition 6 :}

Let $\mathrm{G}=(\mathrm{V}(\mathrm{G}), \mathrm{E}(\mathrm{G}))$ be a graph. A bijection $\mathrm{f}: \mathrm{V}(\mathrm{G}) \rightarrow$ $\{1,2,3, \ldots \ldots, p\}$ is called prime labeling [10,14], if for each edge $e=u v$ in $E(G)$, where $u, v$ are end vertices of e,the $\operatorname{gcd}(\mathrm{f}(\mathrm{u}), \mathrm{f}(\mathrm{v}))=1$.

Definition 7 : A graph that admits prime labeling is called prime graph[10,14].

\section{MAIN RESULTS.}

Theorem 1: The corona graph $C_{n} * K_{1}$ is $H$-cordial for all $n \geq 3$.

Proof : Let $\left\{u_{1}, u_{2}, \ldots \ldots, u_{n}, v_{1}, v_{2}, \ldots \ldots ., v_{n}\right\}$ be the set of vertices of $C_{n} * K_{1}$. The vertices on cycle $C_{n}$ are $u_{1}, u_{2}, \ldots \ldots ., u_{n}$ while $\mathrm{v}_{1}, \mathrm{v}_{2}, \ldots \ldots \ldots, \mathrm{v}_{\mathrm{n}}$ are pendant vertices adjacent to $\mathrm{u}_{1}, \mathrm{u}_{2}$, $\ldots \ldots, \mathrm{u}_{\mathrm{n}}$ respectively.

The labeling function is different when $\mathrm{n}$ is odd and when $\mathrm{n}$ is even.

Hence we consider two cases.

Case i) $: n$ is odd . Case ii) $: n$ is even

Label the edges of $\mathrm{C}_{\mathrm{n}} * \mathrm{~K}_{1}$ as follows:-

Case-i) $n$ is even.

The labeling function for $\mathrm{C}_{\mathrm{n}} * \mathrm{~K}_{1}$ when $\mathrm{n}$ is even is given as follows :-

$f\left(\mathrm{u}_{\mathrm{i}} \mathrm{v}_{\mathrm{i}}\right)= \begin{cases}+1 & \text { if } \mathrm{i} \text { is even } \\ -1 & \text { if } \mathrm{i} \text { is odd } ; 1 \leq \mathrm{i} \leq n\end{cases}$

$f\left(\mathrm{u}_{\mathrm{i}} \mathrm{u}_{\mathrm{i}+1}\right)=\left\{\begin{array}{l}+1 \text { if } \mathrm{i} \text { is odd } \\ -1 \text { if } \mathrm{i} \text { is even } ; 1 \leq \mathrm{i} \leq n ; u_{n+1}=u_{1} .\end{array}\right.$

The induced vertex labels of $C_{n} * K_{1}$ becomes,

$f\left(u_{i}\right)=\left\{\begin{array}{l}-1 ; \text { if } \mathrm{i} \text { is odd } . \\ 1 ; \text { if } \mathrm{i} \text { is even. }\end{array}\right.$

$f\left(v_{i}\right)=\left\{\begin{array}{c}-1 ; \text { if } \mathrm{i} \text { is odd } . \\ 1 ; \text { if } \mathrm{i} \text { is even. }\end{array}\right.$

Thus, when $\mathrm{n}$ is even $\mathrm{f}$ is $\mathrm{H}$-cordial labeling of $\mathrm{C}_{\mathrm{n}} * \mathrm{~K}_{1}$ with $\mathrm{e}_{\mathrm{f}}$ $(+1)=\mathrm{e}_{\mathrm{f}}(-1)=\mathrm{n}$ and $\mathrm{v}_{\mathrm{f}}(+1)=$

$\mathrm{v}_{\mathrm{f}}(-1)=\mathrm{n}$.

\section{Case ii) $\mathrm{n}$ is odd}

The labeling function for $\mathrm{C}_{\mathrm{n}} * \mathrm{~K}_{1}$ when $\mathrm{n}$ is odd is given as follows :-

$f\left(u_{i} v_{i}\right)=\left\{\begin{array}{l}+1 \text { if } i \text { is even } \forall 1 \leq i \leq n-1 \\ -1 \text { if } i \text { is odd } \forall 1 \leq i \leq n-1\end{array}\right.$

$\mathrm{f}\left(\mathrm{u}_{\mathrm{n}} \mathrm{v}_{\mathrm{n}}\right)=1$

$f\left(u_{i} u_{i+1}\right)=\left\{\begin{array}{c}+1 \text { if } i \text { is odd } \forall 1 \leq i \leq n-2 \\ -1 \text { if } i \text { is even } \forall 1 \leq i \leq n-1\end{array}\right.$

$f\left(u_{n} u_{1}\right)=-1$

The induced vertex labels of $\mathrm{C}_{\mathrm{n}} * \mathrm{~K}_{1}$ becomes,

$f\left(u_{i}\right)=\left\{\begin{array}{l}-1 \text { if } i \text { is odd } \\ +1 \text { if } i \text { is even }\end{array}\right.$

$f\left(v_{i}\right)=\left\{\begin{array}{l}-1 \text { if } i \text { is odd } \forall 1 \leq i \leq n-2 \\ +1 \text { if } i \text { is even }\end{array}\right.$

$\mathrm{f}\left(\mathrm{v}_{\mathrm{n}}\right)=1$

Thus, $\mathrm{f}$ is H-cordial labeling of $\mathrm{C}_{\mathrm{n}} * \mathrm{~K}_{1}$ with $\mathrm{e}_{\mathrm{f}}(+1)=$ $\mathrm{e}_{\mathrm{f}}(-1)=\mathrm{n}$ and $\mathrm{v}_{\mathrm{f}}(-1)=\mathrm{v}_{\mathrm{f}}(+1)=\mathrm{n}$.

Illustration1 : Consider $\mathrm{C}_{8} * \mathrm{~K}_{1}$.

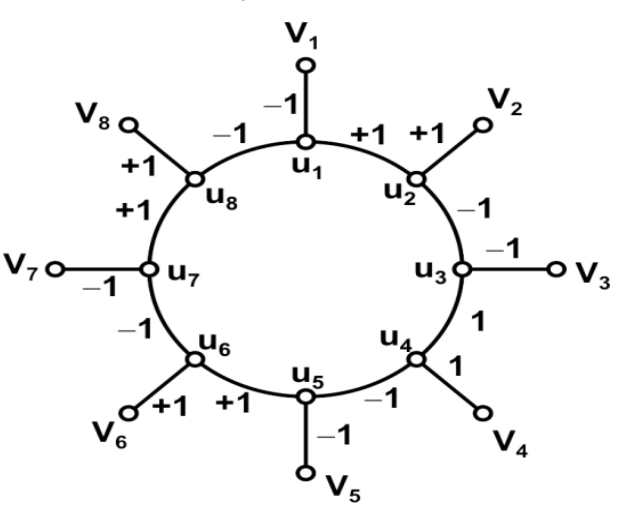

Figure 5 : H-Cordial labeling of $\mathrm{C}_{8} * \mathrm{~K}_{1}$.

Here we get

$f\left(u_{1} v_{1}\right)=-1 \quad f\left(u_{1} u_{2}\right)=1 \quad f\left(u_{1}\right)=-1 \quad f\left(v_{1}\right)=-1$

$f\left(u_{2} v_{2}\right)=1 \quad f\left(u_{2} u_{3}\right)=-1 \quad f\left(u_{2}\right)=1 f\left(v_{2}\right)=1$

$\mathrm{f}\left(\mathrm{u}_{3} \mathrm{v}_{3}\right)=-1 \quad \mathrm{f}\left(\mathrm{u}_{3} \mathrm{u}_{4}\right)=1 \quad \mathrm{f}\left(\mathrm{u}_{3}\right)=-1 \quad \mathrm{f}\left(\mathrm{v}_{3}\right)=-1$

$\mathrm{f}\left(\mathrm{u}_{4} \mathrm{v}_{4}\right)=1 \quad \mathrm{f}\left(\mathrm{u}_{4} \mathrm{u}_{5}\right)=-1 \quad \mathrm{f}\left(\mathrm{u}_{4}\right)=1 \quad \mathrm{f}\left(\mathrm{v}_{4}\right)=1$

$f\left(u_{5} v_{5}\right)=-1 \quad f\left(u_{5} u_{6}\right)=1 \quad f\left(u_{5}\right)=-1 \quad f\left(v_{5}\right)=-1$

$\mathrm{f}\left(\mathrm{u}_{6} \mathrm{v}_{6}\right)=1 \mathrm{f}\left(\mathrm{u}_{6} \mathrm{u}_{7}\right)=-1 \quad \mathrm{f}\left(\mathrm{u}_{6}\right)=1 \mathrm{f}\left(\mathrm{v}_{6}\right)=-1$

$\mathrm{f}\left(\mathrm{u}_{7} \mathrm{v}_{7}\right)=-1 \mathrm{f}\left(\mathrm{u}_{7} \mathrm{u}_{8}\right)=1 \mathrm{f}\left(\mathrm{u}_{7}\right)=-1 \mathrm{f}\left(\mathrm{v}_{7}\right)=-1$

$\mathrm{f}\left(\mathrm{u}_{8} \mathrm{v}_{8}\right)=1 \mathrm{f}\left(\mathrm{u}_{8} \mathrm{u}_{1}\right)=-1 \mathrm{f}\left(\mathrm{u}_{8}\right)=1 \mathrm{f}\left(\mathrm{v}_{8}\right)=1$

Thus, when $\mathrm{n}$ is even, $\mathrm{f}$ is $\mathrm{H}$-Cordial labeling of $\mathrm{C}_{8} * \mathrm{~K}_{1} \mathrm{e}_{\mathrm{f}}(-1)$ $=\mathrm{e}_{\mathrm{f}}(1)=8$ and $\mathrm{v}_{\mathrm{f}}(-1)=\mathrm{v}_{\mathrm{f}}(+1)=8$.

Illustration 2: Consider $\mathrm{C}_{9} * \mathrm{~K}_{1}$. 


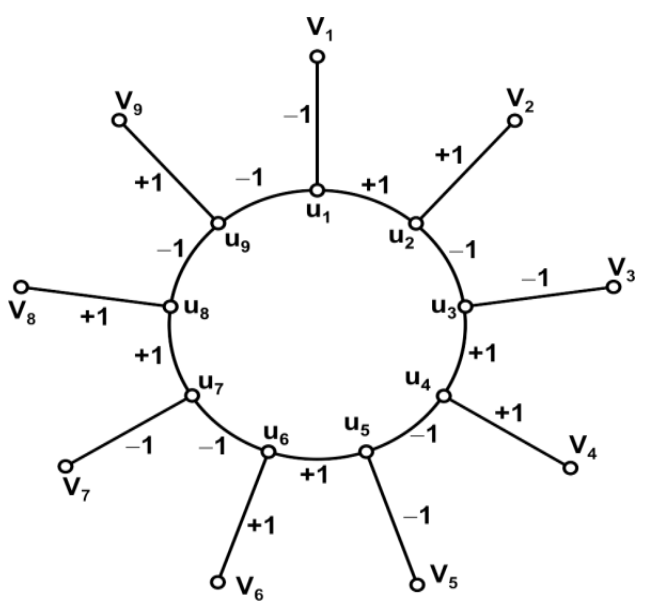

Figure 6: H-Cordial labeling of $\mathrm{C}_{9} * \mathrm{~K}_{1}$.

Here we get ;

$$
\begin{aligned}
& \mathrm{f}\left(\mathrm{u}_{1} \mathrm{v}_{1}\right)=-1 \mathrm{f}\left(\mathrm{u}_{1} \mathrm{u}_{2}\right)=1 \mathrm{f}\left(\mathrm{u}_{1}\right)=-1 \mathrm{f}\left(\mathrm{v}_{1}\right)=-1 \\
& \mathrm{f}\left(\mathrm{u}_{2} \mathrm{v}_{2}\right)=1 \mathrm{f}\left(\mathrm{u}_{2} \mathrm{u}_{3}\right)=-1 \mathrm{f}\left(\mathrm{u}_{2}\right)=-1 \mathrm{f}\left(\mathrm{v}_{2}\right)=1 \\
& \mathrm{f}\left(\mathrm{u}_{3} \mathrm{v}_{3}\right)=-1 \mathrm{f}\left(\mathrm{u}_{3} \mathrm{u}_{4}\right)=1 \mathrm{f}\left(\mathrm{u}_{3}\right)=-1 \mathrm{f}\left(\mathrm{v}_{3}\right)=-1 \\
& \mathrm{f}\left(\mathrm{u}_{4} \mathrm{v}_{4}\right)=1 \mathrm{f}\left(\mathrm{u}_{4} \mathrm{u}_{5}\right)=-1 \mathrm{f}\left(\mathrm{u}_{4}\right)=-1 \mathrm{f}\left(\mathrm{v}_{4}\right)=1 \\
& \mathrm{f}\left(\mathrm{u}_{5} \mathrm{v}_{5}\right)=-1 \mathrm{f}\left(\mathrm{u}_{5} \mathrm{u}_{6}\right)=1 \mathrm{f}\left(\mathrm{u}_{5}\right)=-1 \mathrm{f}\left(\mathrm{v}_{5}\right)=-1 \\
& \mathrm{f}\left(\mathrm{u}_{6} \mathrm{v}_{6}\right)=1 \mathrm{f}\left(\mathrm{u}_{6} \mathrm{u}_{7}\right)=-1 \mathrm{f}\left(\mathrm{u}_{6}\right)=-1 \mathrm{f}\left(\mathrm{v}_{6}\right)=-1 \\
& \mathrm{f}\left(\mathrm{u}_{7} \mathrm{v}_{7}\right)=-1 \mathrm{f}\left(\mathrm{u}_{7} \mathrm{u}_{8}\right)=1 \mathrm{f}\left(\mathrm{u}_{7}\right)=-1 \mathrm{f}\left(\mathrm{v}_{7}\right)=-1 \\
& \mathrm{f}\left(\mathrm{u}_{8} \mathrm{v}_{8}\right)=1 \mathrm{f}\left(\mathrm{u}_{8} \mathrm{u}_{1}\right)=-1 \mathrm{f}\left(\mathrm{u}_{8}\right)=-1 \mathrm{f}\left(\mathrm{v}_{8}\right)=1
\end{aligned}
$$

$\mathrm{f}\left(\mathrm{u}_{9} \mathrm{v}_{9}\right)=1$

Thus, when $\mathrm{n}$ is odd, $\mathrm{f}$ is $\mathrm{H}-$ Cordial labeling of $\mathrm{C}_{\mathrm{n}} * \mathrm{~K}_{1}$ with $\mathrm{e}_{\mathrm{f}}(-1)=\mathrm{e}_{\mathrm{f}}(+1)=9$ and $\mathrm{v}_{\mathrm{f}}(+1)=\mathrm{v}_{\mathrm{f}}(-1)=9$.

Theorem 2: The corona graph $\mathrm{C}_{\mathrm{n}}{ }^{*} \mathrm{~K}_{1}$ is prime for all $\mathrm{n} \geq 3$.

Proof : Let $\left\{\mathrm{u}_{1}, \mathrm{u}_{2} \ldots, \mathrm{u}_{\mathrm{n}}, \mathrm{v}_{1}, \mathrm{v}_{2}, \ldots, \mathrm{v}_{\mathrm{n}}\right\}$ be set of vertices of $\mathrm{C}_{\mathrm{n}} * \mathrm{~K}_{1}$. The vertices on cycle $\mathrm{C}_{\mathrm{n}}$ are $\mathrm{u}_{1}, \mathrm{u}_{2} \ldots \ldots, \mathrm{u}_{\mathrm{n}}$ while the vertices $\mathrm{v}_{1}, \mathrm{v}_{2}, \ldots \ldots, \mathrm{v}_{\mathrm{n}}$ are pendant vertices adjacent to $\mathrm{u}_{1}, \mathrm{u}_{2} \ldots \ldots, \mathrm{u}_{\mathrm{n}}$ respectively.

The labeling function is different when $\mathrm{n}$ is odd and when $\mathrm{n}$ is even.

Hence we consider two cases.

Case i) $: n$ is odd . Case ii) $: n$ is even.

\section{Case $\mathbf{i}): \mathbf{n}$ is odd.}

When $\mathrm{n}$ is odd, the labeling function is divided into two subcases.

Subcase i): $n \not \equiv 1(\bmod 6)$.

Subcase ii): $\mathrm{n} \equiv 1(\bmod 6)$

Subcase i) : Consider $n \not \equiv 1(\bmod 6)$.

The vertex labeling in this subcase is defined as follows:-

$\mathrm{f}\left(\mathrm{u}_{\mathrm{i}}\right)=\mathrm{i}$ for all $1 \leq \mathrm{i} \leq \mathrm{n}$. and

$\mathrm{f}\left(\mathrm{v}_{\mathrm{i}}\right)=2 \mathrm{n}+1-\mathrm{i}$ for all $1 \leq \mathrm{i} \leq \mathrm{n}$.

Then $\operatorname{gcd}\left(\mathrm{f}\left(\mathrm{u}_{\mathrm{i}}\right), \mathrm{f}\left(\mathrm{u}_{\mathrm{i}+1}\right)\right)=1$ for $1 \leq \mathrm{i} \leq \mathrm{n}-1$ because two consecutive numbers are relatively prime. $\operatorname{gcd}\left(\mathrm{f}\left(\mathrm{u}_{\mathrm{n}}\right), \mathrm{f}\left(\mathrm{u}_{1}\right)\right)=1$ as $\operatorname{gcd}(1, \mathrm{n})=1$.

Further if ' $\mathrm{i}$ ' is odd then " $2 \mathrm{n}+1-\mathrm{i}$ " is even and when ' $\mathrm{i}$ ' is even then " $2 \mathrm{n}+1-\mathrm{i}$ " is odd, hence $\operatorname{gcd}\left(\mathrm{f}\left(\mathrm{u}_{\mathrm{i}}\right), \mathrm{f}\left(\mathrm{v}_{\mathrm{i}}\right)\right)=1$ for $1 \leq \mathrm{i} \leq \mathrm{n}$

Hence labeling is a prime labeling.

Illustration 3:- Prime labeling of $\mathrm{C}_{9} * \mathrm{~K}_{1}$

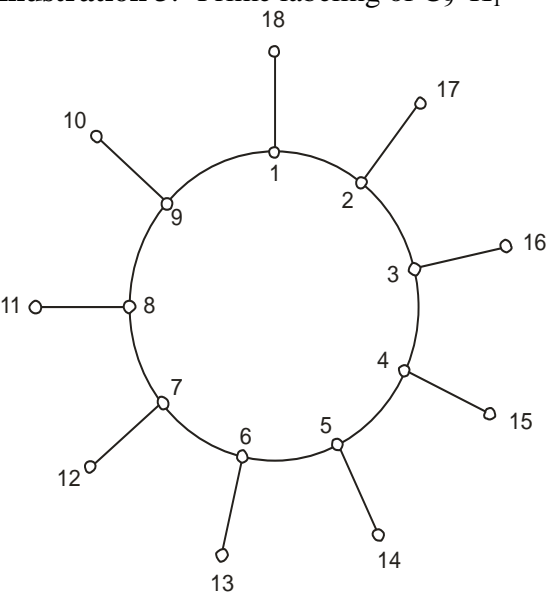

Subcase ii) :- Consider $\mathrm{n} \equiv 1(\bmod 6)$.

The vertex labeling in this subcase is defined as follows :-

$\mathrm{f}\left(\mathrm{u}_{\mathrm{i}}\right)=\mathrm{i}$ for all $1 \leq \mathrm{i} \leq \mathrm{n}$.

$\mathrm{f}\left(\mathrm{v}_{\mathrm{i}}\right)=2 \mathrm{n}+3-\mathrm{i}$ for all $3 \leq \mathrm{i} \leq \mathrm{n}$.

$\mathrm{f}\left(\mathrm{v}_{1}\right)=\mathrm{n}+3 ; \mathrm{f}\left(\mathrm{v}_{2}\right)=\mathrm{n}+2 ; \mathrm{f}\left(\mathrm{v}_{\mathrm{n}}\right)=\mathrm{n}+1$

As in the earlier subcase $\operatorname{gcd}\left(\mathrm{f}\left(\mathrm{u}_{\mathrm{i}}\right), \mathrm{f}\left(\mathrm{u}_{\mathrm{i}+1}\right)\right)=1$ for $1 \leq \mathrm{i} \leq \mathrm{n}-1$ and $\operatorname{gcd}\left(\mathrm{f}\left(\mathrm{u}_{\mathrm{n}}\right), \mathrm{f}\left(\mathrm{u}_{1}\right)\right)=1$.

For $3 \leq \mathrm{i} \leq \mathrm{n}, \operatorname{gcd}\left(\mathrm{f}\left(\mathrm{u}_{\mathrm{i}}\right), \mathrm{f}\left(\mathrm{v}_{\mathrm{i}}\right)\right)=1$ because if ' $\mathrm{i}$ ' is odd then " $2 n+3-i$ " is even and when ' $\mathrm{i}$ ' is even then " $2 n+3-i$ " is odd .

Also $\mathrm{n}$ is odd hence $\operatorname{gcd}(2, \mathrm{n}+2)=1, \operatorname{gcd}(1, \mathrm{n}+3)=1$, $\operatorname{gcd}(\mathrm{n}, \mathrm{n}+1)=1$, hence respectively, $\operatorname{gcd}\left(\mathrm{f}\left(\mathrm{u}_{2}\right), \mathrm{f}\left(\mathrm{v}_{2}\right)\right)=1$, $\operatorname{gcd}\left(\mathrm{f}\left(\mathrm{u}_{1}\right), \mathrm{f}\left(\mathrm{v}_{1}\right)\right)=1, \operatorname{gcd}\left(\mathrm{f}\left(\mathrm{u}_{\mathrm{n}}\right), \mathrm{f}\left(\mathrm{v}_{\mathrm{n}}\right)\right)=1$.

Illustration 4:- Prime labeling of $\mathrm{C}_{13} * \mathrm{~K}_{1}$.

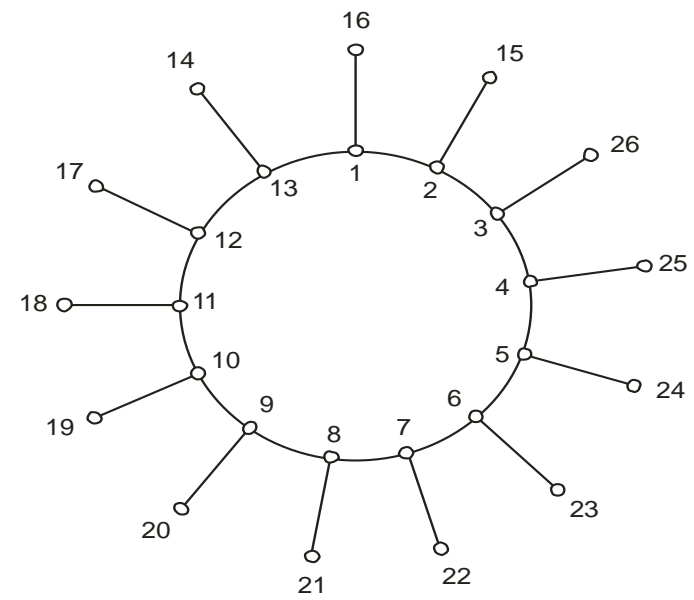

Case ii) : $n$ is even.

When $\mathrm{n}$ is even, the labeling function is divided ino two subcases.

Subcase i): $n \not \equiv 2(\bmod 6)$.

Subcase ii): $\mathrm{n} \equiv 2(\bmod 6)$

Subcase i) : Consider $n \not \equiv 2(\bmod 6)$. 
The vertex labeling in this subcase is defined as follows:-

$\mathrm{f}\left(\mathrm{u}_{\mathrm{i}}\right)=\mathrm{i}$ for all $\mathrm{i}, 1 \leq \mathrm{i} \leq \mathrm{n} . \quad \mathrm{f}\left(\mathrm{v}_{\mathrm{i}}\right)=\mathrm{n}+1+\mathrm{i}$ for all $\mathrm{i}, 1 \leq \mathrm{i} \leq$ $\mathrm{n}-1 . \mathrm{f}\left(\mathrm{v}_{\mathrm{n}}\right)=\mathrm{n}+1$.

Clearly $\operatorname{gcd}\left(\mathrm{f}\left(\mathrm{u}_{\mathrm{i}}\right), \mathrm{f}\left(\mathrm{u}_{\mathrm{i}+1}\right)\right)=1$ for $1 \leq \mathrm{i} \leq \mathrm{n}-1$ and $\operatorname{gcd}\left(f\left(u_{n}\right), f\left(u_{1}\right)\right)=1$

When $i$ is even, $n+1+i$ is odd and when $i$ is odd,$n+1+i$ is even therefore, for $1 \leq \mathrm{i} \leq \mathrm{n}-1, \operatorname{gcd}\left(\mathrm{f}\left(\mathrm{u}_{\mathrm{i}}\right), \mathrm{f}\left(\mathrm{v}_{\mathrm{i}}\right)\right)=1$.Also $\operatorname{gcd}\left(f\left(u_{n}\right), f\left(v_{n}\right)\right)=1 \quad$ as $\operatorname{gcd}(n, n+1)=1$.

Illustration 5:- Prime labeling of $\mathrm{C}_{10} * \mathrm{~K}_{1}$.

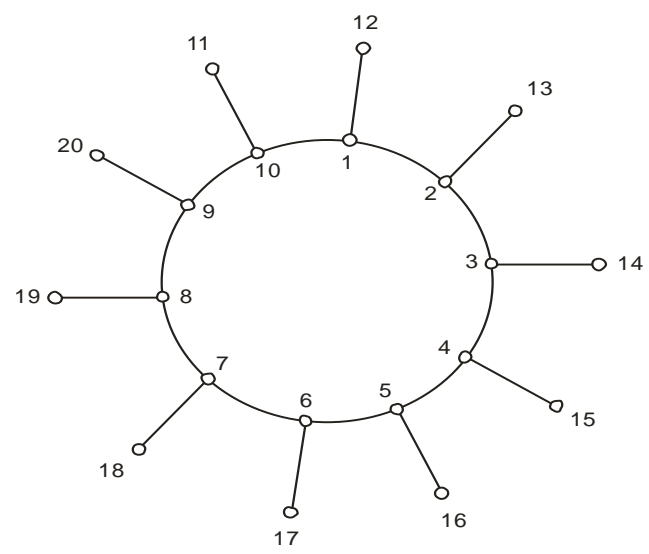

Subcase ii) :- Consider $n \equiv 2(\bmod 6)$.

The vertex labeling in this subcase is defined as

follows :-

$\mathrm{f}\left(\mathrm{u}_{\mathrm{i}}\right)=\mathrm{i}$ for all $1 \leq \mathrm{i} \leq \mathrm{n}$

$\mathrm{f}\left(\mathrm{v}_{\mathrm{i}}\right)=\mathrm{n}-1+\mathrm{i}$ for all $2 \leq \mathrm{i} \leq \mathrm{n}-2$.

$f\left(v_{1}\right)=2 n-2$.

$\mathrm{f}\left(\mathrm{v}_{\mathrm{n}-1}\right)=2 \mathrm{n}$.

$\mathrm{f}\left(\mathrm{v}_{\mathrm{n}}\right)=2 \mathrm{n}-1$.

As explained in earlier sub-cases it can be seen that labeling is a prime labeling.

Illustration 6:- Prime labeling of $\mathrm{C}_{14} * \mathrm{~K}_{1}$.

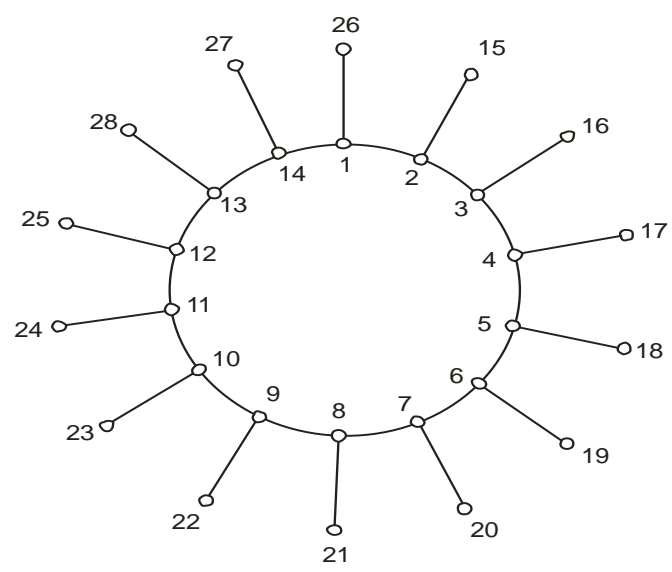

\section{CONCLUSION}

The H-cordial labeling and prime labeling is given to the corona graph $\mathrm{C}_{\mathrm{n}} * \mathrm{~K}_{1}$. The $\mathrm{H}$-cordial labeling and prime labeling of many symmetrical graphs is yet to be known. It is interesting to apply these labeling to certain classes of graph. The structure of the corona graph suggests that computer programmes may be obtained for given labelings. Labeling of discrete structure is a potential area of research due to its diversified applications and it is very interesting to investigate whether any graph or graph family admits a particular labeling or not? Here we contribute two results in the context of prime labeling and sequential labeling.

\section{OPEN PROBLEMS}

To find whether a particular graph has different labelings.

Similar results can be obtained in the context of different graph labeling techniques.

\section{REFERENCES}

[1] Lee,S.M. Wue,I. and Yeh,I.(1988).On the amalgamation of prime graphs, Bull Malayasian Math. Soc.,(2)11,59-67.

[2] Christian Barrientos.(2002). Graceful labeling of Chains and Corona graphs. Bull.Inst.Combin.Appli,Vol-34,pp. 17-26.

[3] Timothy A. Redl .(2003). Graceful Graphs and Graceful labeling: Two mathematical programming formulations and some other new results. Computational and Applied mathematics; pp. 1-13.

[4] Christian Barrientos .(2005). Graceful graphs with pendant edges. Australian journal of Combinatorics, Vol33,pg:99-107.

[5] Christian Barrientos.(2002). Equitable labeling of Corona graphs. JCMCC,Vol- 41,pp. 139-149.

[6] Harary, F. (1972). Graph Theory. Addison-Wesley Publishing Company.

[7] Gallian, J.A. (2011).A dynamic survey of graph labeling. Electronic Journal of Combinatorics,DS6.

[8] Devraj, J. and Prem Delphy, P. (2011).On H-cordial graphs.International J. of Math. Sci. \& Engg. Appls. (IJMSEA),Vol.5,No.V,pp. 287-296.

[9] Grace, T. (1983).,J. Graph Theory.vol-7.pp 195-203.

[10] Ramya, N.; Rangarajan, K.; Sattanathan, R. (2012). On prime labeling of some classes of graph. International Journal of Computer applications, 44(4), pp 1-3.

[11] Yung-Ling Lai and General J. Chang. (2003). On the profile of the corona of two graphs. National Science council under grant NSC92-2115-m002-015, , 1-10.

[12] Rosa, A. (1966). On certain valuations of the vertices of a graph. Theory of Graphs (International symposium, Rome, Gordon and Breach, N.Y. and Dunod Paris),pp. 349-355.

[13] Yilmaz,R. and Cahit,I.,(1997). E-Cordial graphs. ARS Combinatoria.251-256

[14] Ramya, N.; Rangarajan, K.; Sattanathan, R. (2011). 4regular graphs and its prime labeling. IJCGTA. 